\title{
Unexpected patterns of facilitatory grazing revealed by quantitative imaging
}

\author{
A. J. Underwood, R. J. Murphy* \\ Centre for Research on Ecological Impacts of Coastal Cities, Marine Ecology Laboratories A11, University of Sydney, \\ Sydney, New South Wales 2006, Australia
}

\begin{abstract}
Micro-algae (the principal food of intertidal gastropods) were quantified in areas surrounding mid-shore refuges of the intertidal snail Nerita atramentosa to test the hypothesis that removal of important grazers would lead to more micro-algae. Digital colour-infrared imagery provided independent quantitative measurements of amounts of chlorophyll (as an index of amounts of micro-algae) over small areas through time. To determine the effect of grazing on micro-algal abundance, cages were used to exclude animals from refuges. Other refuges were left uncaged or had partial, control cages. Contrary to predictions, amounts of micro-algae in areas close to refuges from which $N$. atramentosa had been excluded were smaller than in controls, suggesting facilitatory effects of $N$. atramentosa on micro-algal growth or survivorship. Facilitation may occur because of decreased grazing by the limpet Cellana tramoserica where $N$. atramentosa (a competitive dominant) are present or to facilitatory effects of $N$. atramentosa directly on the micro-algae. To unravel complex ecological interactions involving grazing around refuges and the impact of grazing on ecological structure and function it is necessary to make repeated, independent measurements through time. Remote-sensing provided information on distribution of food that would be difficult or impossible to achieve using conventional methods. This research identified complexities and interactions that have implications for the study of grazing effects across many terrestrial, intertidal and marine habitats.
\end{abstract}

KEY WORDS: Chlorophyll $\cdot$ Facilitation $\cdot$ Competition $\cdot$ Reflectance $\cdot$ Remote-sensing $\cdot$ Micro-algae Resale or republication not permitted without written consent of the publisher

\section{INTRODUCTION}

The role of herbivores in the structure and dynamics of assemblages is the subject of continuing ecological research (Underwood \& Denley 1984, Pace et al. 1999, Brown et al. 2001, del-Val \& Crawley 2005). Intensity of grazing by many species of herbivores is known to be greater in areas close to their home refuges, causing a reduction in vegetation in areas near the boundary of a refuge relative to areas further away (Levings \& Garrity 1983). Gradients in abundance and/or composition of vegetation with increasing distance from refuges termed grazing haloes - have been observed in terrestrial, intertidal and other marine habitats (reviewed by Huntley 1991). Grazing haloes can be readily observed and quantified where changes in vegetation are profound or occur over large (metres to $10 \mathrm{~s}$ of metres) spatial scales, as is the case for some species of sea urchins (Ogden et al. 1973), foraging lagomorphs (McIntire \& Hik 2005), parrotfish (Macia \& Robinson 2005), prairie dogs (Whicker \& Detling 1988) and assemblages of small animals (Bartholomew 1970). In intertidal environments, many molluscan herbivores feed on micro-algae (e.g. diatoms, Cyanobacteria, propagules and germlings of macro-algae) on and in intertidal rocky surfaces (Hill \& Hawkins 1991). Many of these herbivores take refuge in rock-pools, crevices or hollows to avoid stress due to desiccation or heat during low tide (reviewed by Brosnan 1992). Within any section of rocky shore, interactions of grazers and refuges can therefore create grazing 'haloes', which are often manifested as reduced amounts of algal foods close to a refuge or as bare areas which gradually give way to crustose or foliose algae (Levings \& Garrity 
1983). Such haloes in intertidal areas tend to be much smaller ( $\mathrm{cm}$ rather than metres) than in terrestrial habitats, but, at these small scales, grazing has very large effects on the structure and dynamics of assemblages, particularly on the development of macroalgae (Underwood 1980) and recruitment of barnacles and other dominant users of space (see particularly Dayton 1971).

Understanding the consequences of grazing on rocky shores has, however, been constrained by the small scales at which grazers operate, but which are integrated to cause shore-wide effects. These have made it difficult to test hypotheses about grazing because quantifying the amount of algal (or micro-algal) biomass around intertidal refuges is difficult. Problems include the following: (1) areas to be sampled are very small, making it difficult or impossible to acquire independently replicated samples through time; (2) biomass of resources used by grazers is estimated in the laboratory from samples of rock by extracting chlorophyll (an index of biomass) and quantifying it spectrophotometrically (Underwood \& Creese 1976); (3) sampling is therefore generally very time-consuming and destructive, making it impossible to test hypotheses about time-courses of processes or the influences of spatial patterns of distribution of resources on the behaviour (e.g. foraging excursions) of the grazers.

As a result of the difficulties, relatively few studies have examined patterns of grazing around refuges in intertidal areas. Levings \& Garrity (1983) found that areas of rock up to $10 \mathrm{~cm}$ away from refuges were bare, but the cover of crustose algae increased with increasing distance from the refuge. Similarly, influences of grazers on a tropical rocky shore extended 50 to $100 \mathrm{~cm}$ from a refuge (Williams et al. 2000). Smaller algal biomass was found within a $5 \mathrm{~cm}$ band around refuges inhabited by high-shore littorinids (Stafford \& Davis 2005). Grazing haloes are not only characterized by changes in biomass, but also by changes in composition and photosynthetic capacity of the algal assemblages (Kaehler \& Froneman 2002).

This study investigated distributions of micro-algal biomass around mid-shore refuges (pools) used by grazing snails Nerita atramentosa on a temperate rocky shore. This species is an important grazer and a dominant competitor for food (Underwood 1984a). A new imaging technique was used to acquire contiguous measurements of chlorophyll (an index of microalgal biomass) at great $\left(<0.5 \mathrm{~mm}^{2}\right)$ spatial resolution (Murphy et al. 2006). The technique enables multiple independent measurements of chlorophyll, nondestructively, over small areas of rock, enabling appropriate replication and sampling at intervals during experiments. Experimental rock-pools had been made in 1986 as part of other projects (see Underwood \&
Skilleter 1996). Numerous N. atramentosa individuals occupied the pools during low tide and grazed over the surrounding rocks during high tide. This pattern of use of shelter and more extensive grazing often leads to haloes, or differences in amounts of micro-algae away from the edge of the pools. This study described experiments to investigate the spatial consequences of grazing as an influence on amounts of chlorophyll over small distances (a few $\mathrm{cm}$ ).

\section{MATERIALS AND METHODS}

Field location and experimental setup. The experiment was done on a sandstone rock-platform at the Cape Banks Scientific Marine Research Area, NSW, Australia, using experimental, circular rock-pools originally made as part of other experiments. Pools were $15 \mathrm{~cm}$ in diameter by a mean of $5 \mathrm{~cm}$ deep, in a midshore area measuring approximately $15 \times 15 \mathrm{~m}$. The experiment started December 2005 (Austral summer) and ended in May 2006.

We proposed that micro-algae will develop faster and to greater amounts in areas around a refuge from which Nerita atramentosa are excluded compared with controls, because the snails will move away and no longer influence the local distribution of micro-algae. To test this, 4 replicate pools were randomly assigned to each of 3 treatments (Fig. 1). Grazers were excluded from pools using a rigid stainless-steel mesh, anchored to the bottom of the pool using a single bolt (Full Cage treatment; FC). Partial cages were used to control for artefacts due to the cages; these were similar to the FC treatment, except that a small gap between the rock

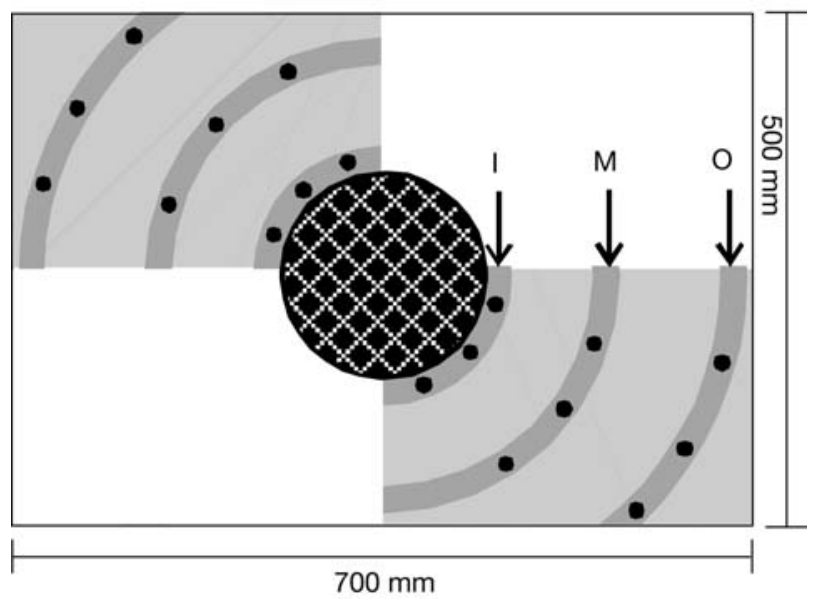

Fig. 1. Diagram of experimental area with a full cage (FC). Encrusting algae were removed from the rectangular areas shown as grey. The hatched circle is the cage over the pool; I, M, O show the inner middle and outer annuli sampled. Black dots represent wax disks used to estimate amount of grazing in each annulus 
and the cage allowed free movement of animals into and out of the pool (Partial Cage treatment; PC). Nerita atramentosa were observed to move in and out of these pools. Control pools did not have a cage (No Cage treatment; NC).

The natural assemblages in the pools at low tide consisted of large numbers of Nerita atramentosa and smaller numbers of Bembicium nanum, Austrocochlea porcata and the limpets Cellana tramoserica. Thick encrusting and foliose macro-algae grew on the base and sides of the pools and on the surrounding rocks.

Algal assemblages on the rock-platform were mainly Cyanobacteria (Anacystis sp.), with small numbers of diatoms and the encrusting macro-algae Ralfsia verrucosa and Hildenbrandia rubra (Underwood 1984a, P. Rang unpubl. data). Many intertidal gastropods eat micro-algae, including propagules and germlings of macro-algae. Nerita aramentosa do not graze on foliose or encrusting macro-algae (Murphy \& Underwood 2006). Measuring chlorophyll as an index of micro-algal food is inaccurate where encrusting algae are present, because micro-algae have less chlorophyll per unit area than do macro-algae, causing large variability in amounts of measured chlorophyll unrelated to the amount of food available to grazers (Underwood 1984 b). All animals were temporarily relocated to adjacent areas, so that algae could be removed from the 70 $\times 50 \mathrm{~cm}$ areas around experimental rock-pools using scrapers, wire brushes and a small amount of hydrochloric acid. To facilitate the return of normal functioning of the habitat, only half of the rock surrounding each pool was cleared of algae (Fig. 1), creating an experimental area of rock-surface of $1660 \mathrm{~cm}^{2}$ (i.e. half of $70 \times 50 \mathrm{~cm}$ minus the area occupied by the pool). Cages were installed during the following low tide.

Colour-infrared imagery. Colour-infrared (CIR) imagery has recently been developed to quantify amounts of chlorophyll as an index of amount of algal material on the surface of soft sediments and intertidal rock-platforms (Murphy et al. 2004, 2006). The technique allows chlorophyll to be quantified non-destructively, at very small scales, over distances of 1 to $2 \mathrm{~m}$. Each pixel in the image is effectively a separate measurement of chlorophyll and typically covers an area of rock $<1 \mathrm{~mm}^{2}$. CIR imagery therefore provides contiguous information on the variability of chlorophyll over the rock surface at a spatial resolution that is impossible to achieve using conventional sampling techniques.

CIR images quantify the amount of light reflected from the rock platform in 3 spectral bands: green (525 to $575 \mathrm{~nm})$, red (645 to $689 \mathrm{~nm}$ ) and near infrared (NIR, 758 to $833 \mathrm{~nm}$ ). These reflectances are recorded as separate images. Algae and higher-plants are very reflective in the NIR because their internal structures scatter light. At red wavelengths, chlorophyll absorbs light for photosynthesis. By quantifying the amount of light absorbed at red wavelengths, relative to the amount scattered at NIR wavelengths, the amount of chlorophyll can be estimated by dividing the value of each pixel in the NIR image by the corresponding value in the red image. The ratio also removes variation caused by differences in brightness of the rocksurface within the image. Results have been verified in comparisons with spectrophotometric methods (Murphy et al. 2006).

Field sampling. The CIR camera (Redlake MASD) with a Sigma $14 \mathrm{~mm}$ f/2.8 ES/HSM super-wide-angle lens was mounted on a metal stand $1.5 \mathrm{~m}$ above and normal to the rock surface, giving an image of $654 \times$ $488 \mathrm{~mm}$ of rock-platform, each pixel quantifying chlorophyll over an area $\sim 0.47 \mathrm{~mm}^{2}$. Images were acquired from each rock-pool 1, 44, 75 and $117 \mathrm{~d}$ after removal of the algae. This period allows recovery of microflora to unscraped levels (MacLulich 1986).

Ratio images were constructed by dividing the pixel values in the NIR band by those in the red. Values of the resulting ratios are proportional to the amount of chlorophyll (algal biomass) on the rock surface (full details in Murphy et al. 2006).

Data from images. NIR:red ratios were calculated in areas that had previously been cleared of macro-algae at 3 distances from the edge of a rock-pool. A template was created comprising 3 (the inner, middle and outer) annuli at the 3 distances to be sampled (Fig. 1). The centres of the inner, middle and outer annuli were $15 \mathrm{~mm}, 118 \mathrm{~mm}$ and $221 \mathrm{~mm}$, respectively, from the edge of the rock-pool. The template was overlaid onto each image; areas to be sampled were then identified within each annulus. To prevent operator bias, unprocessed CIR images, which did not indicate the amount of algae present, were used to locate samples. Individual samples were $18 \times 18$ pixels in size (i.e. equivalent to an area of rock $\sim 64 \mathrm{~mm}^{2}$ ). Twenty random areas (10 from each side of the rock-pool) were sampled within each annulus. These sample areas were then overlaid on the corresponding NIR:red ratio image and the pixel data within each of the sample areas were extracted from the image and averaged. By taking small, replicated samples to estimate amounts of chlorophyll in the experimental areas, it is possible to sample different (i.e. independent) areas on subsequent occasions.

Counts of animals and measurements of grazing. Animals in each pool and in the surrounding area (Fig. 1) were counted on 18 occasions during the experiment. Near the end of the experiment (on 5 June 2006), grazing activity was measured using wax disks approximately $12 \mathrm{~mm}$ in diameter and $113 \mathrm{~mm}^{2}$ (Thompson et al. 1997). Six pools (2 per treatment) 
were randomly selected. Wax discs were embedded in holes drilled into the rock surface so that their surfaces were level with the surrounding rock. Six replicate discs were put into each annulus (3 on each side of the pool) in each experimental area (see Fig. 1). Disks were retrieved 8 d later (13th June 2006) and grazing marks counted as in Forrest et al. (2001).

\section{RESULTS}

\section{Numbers of animals}

There were more Nerita atramentosa individuals than any other species in the NC and PC pools (illustrated for $N$. atramentosa in Fig. 2a,b). There were very few animals inside the FC pools; these were mostly juvenile $B e$ mbicium nanum and Austrocochlea porcata (Fig. 2c), so

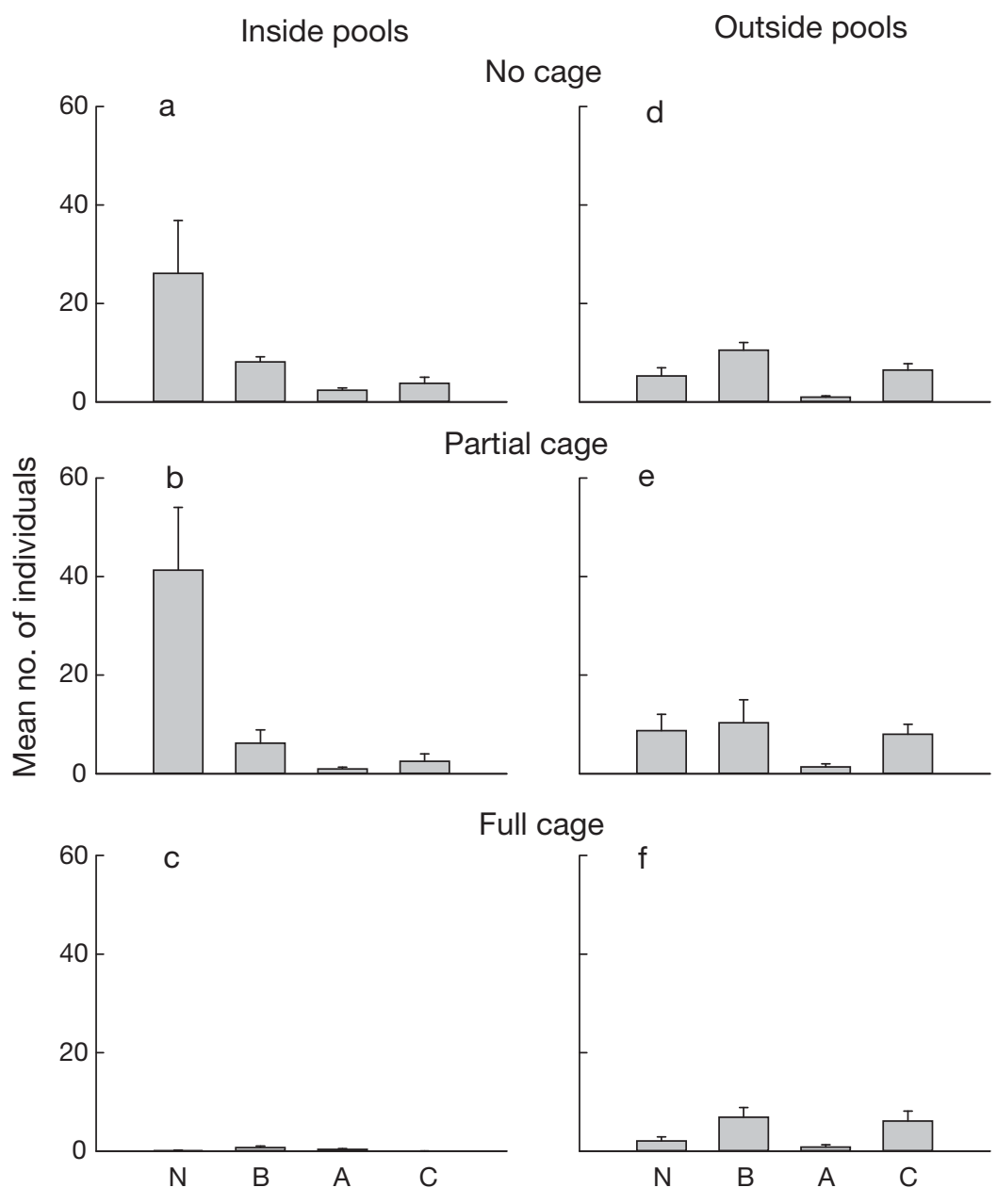

Fig. 2. Mean $(+\mathrm{SE})$ numbers of animals (per $176 \mathrm{~cm}^{2}$ ) in and surrounding rock-pools in each treatment (from 4 replicate pools sampled 18 times): N (Nerita atramentosa); B (Bembicium nanum); A (Austrocochlea porcata); C (Cellana tramosenica) cages effectively excluded $N$. atramentosa. The numbers of animals in the experimental areas surrounding the pools were similar for the NC and PC treatments (Fig. 2d,e), but there were fewer $N$. atramentosa individuals around the FC treatment (Fig. 2f). As support for this conclusion, the numbers around the pools of each treatment (summed over the replicate pools) were compared for each species, at various times of sampling. Analyses of these counts of animals are made difficult because counts through time are unlikely to be independent when times of sampling are close together. Nevertheless, B. nanum and Cellana tramoserica had significantly different totals among treatments on 9 and 7 of 18 sampling occasions, respectively $\left(\chi^{2}, 2 \mathrm{df}, \mathrm{p}<0.05\right.$ for each occasion). There was, however, no pattern in which treatments differed (Table 1). A. porcata were absent from surrounds of all pools on 2 sampling occasions (they were in the pools); there was, however, no pattern among treatments, even though numbers varied among treatments on 6 of the 16 occasions $\left(\chi^{2}, 2 \mathrm{df}, \mathrm{p}<0.05\right)$.

In contrast, numbers of Nerita atramentosa were different among treatments on 16 of the 18 sampling days $\left(\chi^{2}\right.$, $2 \mathrm{df}, \mathrm{p}<0.001$ for each of these occasions) and on the great majority of occasions, the numbers were smallest around the treatment with an FC (Table 1). Even though the times of sampling do not generate completely independent data, there can be little doubt that only $N$. atramentosa were reduced in numbers around caged pools, presumably because of the removal of the pool as a component of habitat.

These data are shown only to demonstrate that experimental cages substantially reduced the numbers of grazers in the pools and the numbers of Nerita atramentosa outside the pools. Only the numbers outside matter for experimental comparisons.

\section{Amount of chlorophyll}

At each time of sampling, there were significant differences in amounts of chlorophyll, which varied with the position around experimental pools and differently from one treatment to another (see significant $\mathrm{R} \times \mathrm{P}(\mathrm{T})$ interactions in Table 2). Patterns in the data were therefore analysed by multiple comparisons (Student-Newman-Keuls [SNK] tests) of 
Table 1. Summary of analyses of numbers of animals around experimental pools (see Fig. 2d-f). Data are number of occasions out of 18 times of sampling for Bembicium nanum, Cellana tramoserica and Nerita atramentosa and 16 times for Austrocochlea porcata throughout the experiment when total numbers were greatest (rank 1), medium (2) or smallest (3) in the 3 experimental treatments. Ties have been averaged. $\chi^{2} 4 \mathrm{df}$ indicates the extent of non-randomness from an Anderson test, but note that data are not independent and probabilities are unreliable

\begin{tabular}{|c|c|c|c|c|}
\hline \multirow{3}{*}{$\begin{array}{l}\text { Rank } \\
\text { Austrocochlea porcata }\end{array}$} & \multirow{2}{*}{\multicolumn{2}{|c|}{$\begin{array}{c}\text { No } \\
\text { cage }\end{array}$}} & \multicolumn{2}{|c|}{ - Treatment } \\
\hline & & & \multirow{2}{*}{$\begin{array}{c}\begin{array}{c}\text { Partial } \\
\text { cage }\end{array} \\
5.5\end{array}$} & \multirow{2}{*}{$\begin{array}{c}\begin{array}{c}\text { Full } \\
\text { cage }\end{array} \\
4.5\end{array}$} \\
\hline & 1 & 6 & & \\
\hline & 2 & 6 & 5 & 5 \\
\hline & 3 & 4 & 5.5 & 6.5 \\
\hline & & & & $.6, p<0.95$ \\
\hline \multirow{4}{*}{ Bembicium nanum } & 1 & 9 & 7 & 2 \\
\hline & 2 & 5.5 & 6 & 6.5 \\
\hline & 3 & 3.5 & 5 & 9.5 \\
\hline & & & & $.7, p<0.25$ \\
\hline \multirow[t]{4}{*}{ Cellana tramoserica } & 1 & 5 & 7 & 6 \\
\hline & 2 & 6 & 7.5 & 4.5 \\
\hline & 3 & 7 & 3.5 & 7.5 \\
\hline & & & & $2.7, p<0.75$ \\
\hline \multirow[t]{4}{*}{ Nerita atramentosa } & 1 & 4 & 14 & 0 \\
\hline & 2 & 11.5 & 3.5 & 3 \\
\hline & & 2.5 & 0.5 & 15 \\
\hline & & & \multicolumn{2}{|c|}{$\chi^{2}=70.3, p<10^{-6}$} \\
\hline
\end{tabular}

means in each ring around each pool and by Anderson's tests (Anderson 1959) of rank-orders of means of treatments using pools as 'trials' and ranking each ring for each pool. These latter tests, individually, are not compelling because of small samples ( $n=4$ pools for each treatment), but were consistent over times of sampling. Patterns in these analyses confirmed the summarized means in Fig. 3.

At Time 1, few SNK tests indicated any differences and these were a complete mixture. For example, the inner ring had significantly more chlorophyll than the middle or outer rings in 4 pools of the 12 in the experiment (i.e. 4 in each of 3 treatments); the middle and
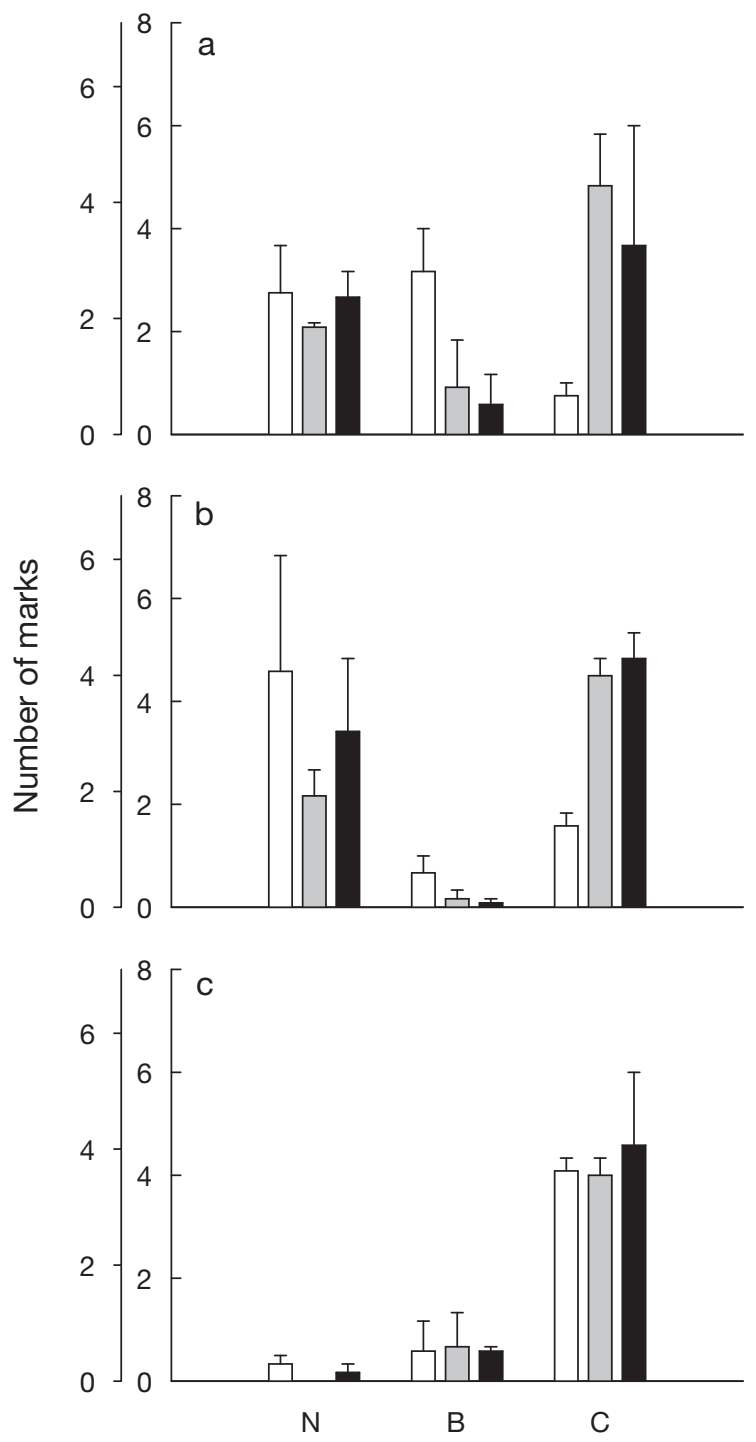

Fig. 3. Mean ( $\mathrm{SE} ; \mathrm{n}=12$ discs, from 2 pools) numbers of grazing marks (inner axis) and number of marks per $\mathrm{cm}^{2}$ (outer axis) on wax disks in the inner (white bar), middle (grey bar) and outer (black bar) annuli: N (Nerita atramentosa); B (Bembicium nanum); C (Cellana tramoserica). (a) No cage; (b) Partial cage; (c) Full cage

Table 2. Analyses of mean amounts of chlorophyll (red:infrared (R:IR) ratios) in experiments at 4 times of sampling. Treatment is No vs. Partial vs. Full cage (fixed); Ring is inner vs. middle vs. outer (fixed); there are 4 randomly chosen pools in each treatment and $\mathrm{n}=20$ samples from each pool at each time. Variances were heterogeneous (Cochran's $C_{i} \mathrm{p}<0.05$ for each time), but this was ignored because of the large df. Because of $\mathrm{R} \times \mathrm{P}(\mathrm{T})$ interactions, only this test is shown

\begin{tabular}{|c|c|c|c|c|c|c|c|c|c|c|c|c|c|}
\hline & \multirow[t]{2}{*}{$\mathrm{df}$} & & \multicolumn{2}{|c|}{ Time $1-$} & \multicolumn{3}{|c|}{ Time 2} & \multicolumn{3}{|c|}{ - Time 3} & - & \multirow{2}{*}{$\begin{array}{c}\text { Time } 4 \\
F\end{array}$} & \multirow[b]{2}{*}{$\mathrm{p}$} \\
\hline & & MS & $F$ & $\mathrm{p}$ & MS & $F$ & $\mathrm{p}$ & MS & $F$ & $\mathrm{p}$ & MS & & \\
\hline Treatment $=\mathrm{T}$ & 2 & 0.040 & & & 0.135 & & & 0.291 & & & 0.452 & & \\
\hline Ring $=\mathrm{R}$ & 2 & 0.099 & & & 0.151 & & & 0.032 & & & 0.588 & & \\
\hline $\mathrm{T} \times \mathrm{R}$ & 4 & 0.004 & & & 0.035 & & & 0.088 & & & 0.178 & & \\
\hline Pools $(\mathrm{T})=\mathrm{P}(\mathrm{T})$ & 9 & 0.187 & & & 0.209 & & & 0.076 & & & 0.145 & & \\
\hline $\mathrm{R} \times \mathrm{P}(\mathrm{T})$ & 18 & 0.006 & 3.64 & $<0.001$ & 0.016 & 2.39 & $<0.002$ & 0.021 & 2.48 & $<0.001$ & 0.056 & 5.18 & $<0.001$ \\
\hline Residual & 684 & 0.002 & & & 0.007 & & & 0.008 & & & 0.011 & & \\
\hline
\end{tabular}


outer rings each had more chlorophyll than in the other rings in 2 pools, respectively. The mixed results indicate noise and no systematic pattern among treatments or rings. This result was supported by Anderson's tests - results were non-significant for all treatments because rings were in different rank orders of chlorophyll from pool to pool in each treatment.

From Time 2 onwards, SNK and Anderson's tests produced very similar outcomes for the control (PC) and NC treatments. Two of the SNK tests were significant, but there was no pattern of difference among the inner, middle and outer rings for these 2 treatments. Anderson's tests were not significant. In contrast, there were significant differences (middle and outer rings had significantly more chlorophyll in SNK tests) for 2 of the 4 pools where there was an FC. Three of the pools had the smallest amount of chlorophyll in the inner ring; the middle ring ranked 1st for 3 pools and the outer ring ranked 1 st or 2 nd in all 4 pools. As a result, Anderson's test was significant $(p<0.05)$ for the FC treatment; the inner ring had least chlorophyll (as shown in Fig. 4c).

This result was stronger at times 3 and 4 . There was no pattern for the control and partially caged pools (inner, middle or outer rings were equally likely to be ranked 1st, 2nd or 3rd for amount of chlorophyll. Six of the 16 SNK tests for the 2 times, 3 treatments and 4 pools were significant, but without any pattern and indicating small-scale spatial patchiness among rings and pools). In contrast, at times 3 and 4, all 4 pools where there was an FC had more chlorophyll in middle and outer rings than in the inner ring, which was significant by Anderson's tests $(p<0.05)$ for each time.

Furthermore, at Time 4, SNK tests showed significantly more chlorophyll in middle or outer rings (which did not differ) than in inner rings for all 4 pools. Thus, as shown in Fig. 4c, there was less chlorophyll in the inner ring in the FC treatment from Time 2 onwards.

\section{Grazing activity}

Analyses of grazing marks were of the same design as those for chlorophyll (as in Table 1), except that there were only 2 replicate pools in each treatment. For Nerita atramentosa, as illustrated in Fig. 3, there was a substantial and significant reduction in number of grazing marks in the FC treatment (mean $=0.17$ ) compared to the PC and NC treatments (3.89, 2.50, respectively), which did not differ (SNK tests of means in each treatment; $F=20.8 ; 2,90 \mathrm{df}, \mathrm{p}<0.001$ after eliminating the factor Pools (Treatments), which was not significant, $F=0.96$; 3,90 df; $p>0.95$; see Under-
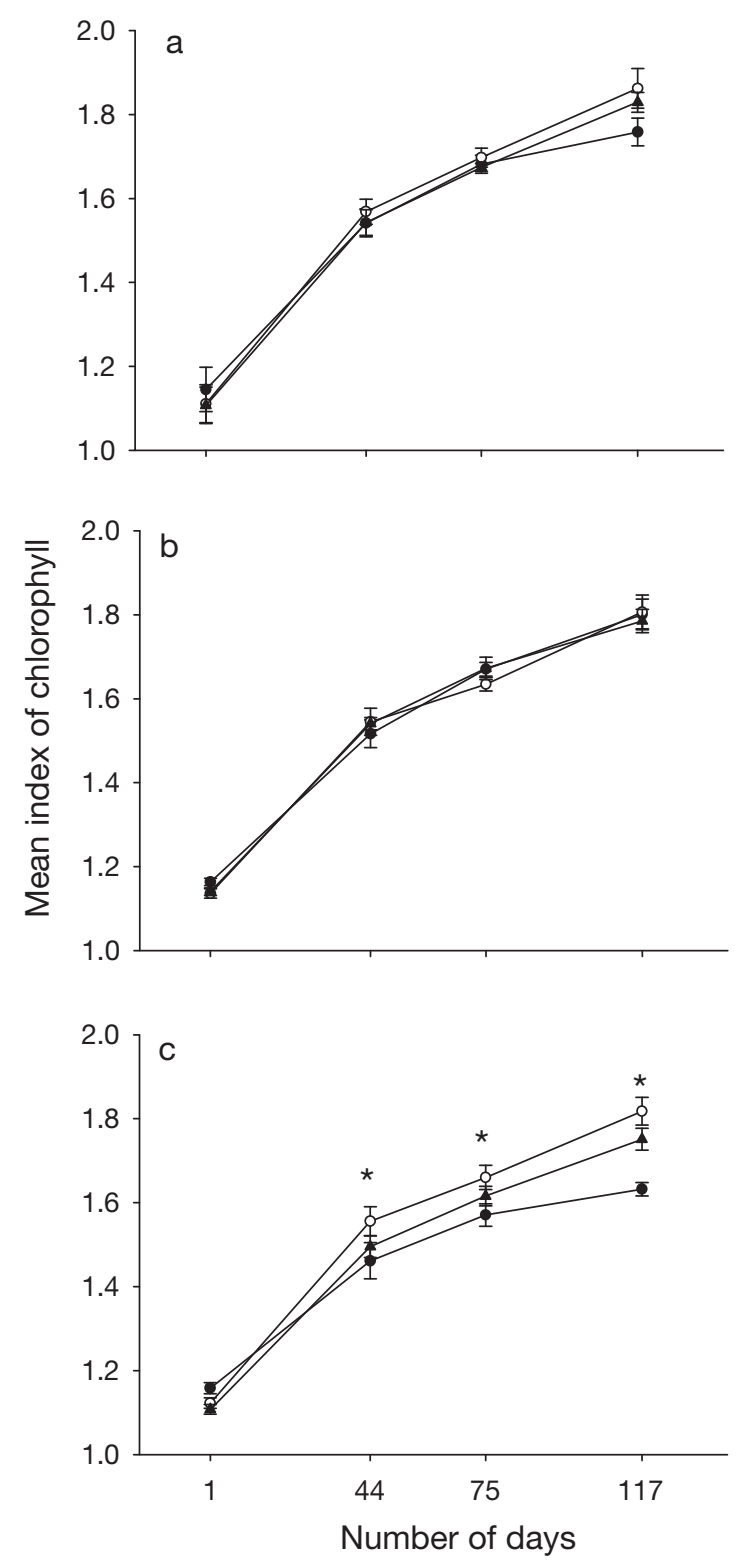

Fig. 4. Mean $\left( \pm \mathrm{SE}_{;} \mathrm{n}=4\right)$ amount of chlorophyll (NIR:red ratio) on different days after removal of algae. Asterisks above data points indicate level of significance $(\mathrm{p}<0.05)$. (a) No cage; (b) partial cage; (c) full cage. o: inner; O: middle; A: outer annuli

wood (1997) for explanation). Other experimental factors in the analysis (Rings, Treatment $\times$ Ring interaction) were not significant (all p > 0.50).

Grazing-marks due to Cellana tramoserica were significantly increased in the inner ring where there were FCs (Fig. 3c, compared with Fig. 3a,b). Mean numbers of marks were significantly less in the inner than in the mid- or outer rings in the $\mathrm{NC}$ and $\mathrm{PC}$ treatments, but not in the FC treatment $(\mathrm{p}<0.05$; SNK comparisons of 
rings in each treatment). There were more marks in the inner ring of the FC treatment (SNK tests for differences among treatments in each ring, $\mathrm{p}<0.05)$. This interaction is clearly visible in Fig. 3.

For Bembicium nanum, there were no differences in amounts of grazing for any ring or treatment (Fig. 3), despite the larger mean number of marks in the inner ring of the NC Treatment (Fig. 3a).

\section{Numbers of animals and amount of chlorophyll}

The mean amount of chlorophyll in each annulus was compared with the average count of animals recorded during the month preceding the dates of sampling (i.e. the month preceding Day 44, Day 75 and Day 117 of the experiment, respectively; Table 1). This was done only for the NC and PC Treatments because there were so few Nerita atramentosa individuals in the FC areas (see Fig. 2) and was not analysed for Austrocochlea porcata because there were few individuals of this species anywhere. Numbers of $N$. atramentosa in the inner and middle annulus of the NC and PC treatments were significantly negatively correlated with micro-algal biomass on Day 44 of the experiment $(\mathrm{r}=0.83,-0.81$ for inner and middle annuli, repectively; $\left.6 \mathrm{df}_{;} \mathrm{p}<0.01\right)$. The correlation for the outer annulus was not significant $\left(r=-0.52 ; 6 \mathrm{df}_{;} \mathrm{p}<0.20\right)$ and there were no correlations between the numbers of $N$. atramentosa and amounts of micro-algae on Days 75 and Day 117 (r ranged from -0.37 to +0.30 over the 8 pools for the 3 annuli; all p > 0.30). There were no significant correlations between number of Bembicium nanum or Cellana tramoserica and amounts of chlorophyll for any ring or time. There were also no correlations between numbers of grazing marks and amounts of chlorophyll in different annuli and treatments for any species at any time.

The differences in amounts of chlorophyll between sampling times (mean on Day 75-mean on Day 44; mean on Day 117 - mean on Day 75) were calculated and compared with average numbers of Nerita atramentosa outside the NC and PC pools from 4 times of sampling in each period of time. Day 1 was not used because the numbers of $N$. atramentosa had not been recorded during the previous month. There was a significant positive correlation between numbers of $N$. atramentosa and the change in amount of chlorophyll between Day 44 and Day 75 for each annulus ( $r=0.94,0.80,0.91$, respectively, for inner, middle and outer annuli; $6 \mathrm{df}$, all $\mathrm{p}<0.01$ ). There was, however, no correlation between numbers of $N$. atramentosa and change in amount of biomass between Day 75 and Day 117. There was also no significant correlation between number of Bembicium nanum or
Cellana tramoserica and change in amount of chlorophyll over any time interval.

\section{DISCUSSION}

These experiments identified 2 interesting issues about grazing and interactions among grazers of different species. Cellana tramoserica fared better, i.e. grazed more on rocks near the pools, in the absence of Nerita atramentosa (in the FC treatment). This was anticipated because C. tramoserica is an inferior competitor to $N$. atramentosa when micro-algal food is in limited or inadequate supply (Underwood 1984a). C. tramoserica and $N$. atramentosa have also been shown experimentally to have major losses of weight and increased mortality due solely to increased intraspecific densities (Underwood 1978, 1984b), but deleterious effects on $C$. tramoserica due to interspecific effects of grazing by $N$. atramentosa are marked.

In the presence of large densities of Nerita atramentosa, local densities of Cellana tramoserica are predicted to be reduced because limpets move away. This could be the result of direct interference - behavioural interactions between the species-or because of responses by $C$. tramoserica to reduced availability of food. The former process has not been observed in the interactions between $N$. atramentosa and C. tramoserica, but has been described for the territorial limpets Lottia gigantea on the Californian coast (Stimson 1973) and some species of Patella on rocky shores in South Africa (Branch 1984). In Stimson's (1973) experimental additions and removals of $L$. gigantea, numbers of Acmaea spp. declined and increased, respectively, because the smaller limpets were increasingly or decreasingly being pushed out of a defended, grazed territory by the larger L. giganteg (Wright 1982, Wright \& Shanks 1993). The latter process - limpets moving away from areas of large density - has been demonstrated experimentally for C. tramoserica (Underwood 1988). It has also been shown experimentally that this can be caused at normal density if food supplies are reduced (Mackay \& Underwood 1977). Densities of limpets are sometimes correlated with amounts of micro-algal food in different areas (Forrest et al. 2001).

Here, numbers of Cellana tramoserica did not increase where Nerita atramentosa were removed. Instead, there was an increase in the amount of radular scraping by $C$. tramoserica in the inner areas where $N$. atramentosa had been removed (FC). This was unexpected. This increase could have been due to increased numbers of $C$. tramoserica or increased rates of grazing where $N$. atramentosa had been removed. It could also be due to a shift in spatial cover of grazing by $C$. tramoserica. There was no overall increase in 
numbers of C. tramoserica where $N$. atramentosa were removed, so rates of grazing must have increased. The lattermost explanation (a shift in spatial cover of grazing) could also explain the observed increase if limpets were restricted to grazing in small areas where $N$. atramentosa were present, but were able to graze over wider areas where $N$. atramentosa were removed. When sampled by only a few wax discs, the former situation would probably show scraping on only a few wax discs, making the average small. More widespread grazing would result in more discs being scraped and a larger mean. It would, however, also show decreased variance in amounts of scraping per disc, which did not happen here. Variances among the wax discs in each annulus around each pool for the number of scrapes made by $C$. tramoserica ranged from 1.5 to 17.1 and generally increased with the mean in each annulus for each pool ( $\mathrm{r}=0.49,16 \mathrm{df}, \mathrm{p}<0.05)$. The variances in the innermost annulus where $N$. atramentosa were removed were not smaller than in areas where $N$. atramentosa were present. To determine whether the spatial pattern of scraping is somehow affected by the presence/absence of $N$. atramentosa, appropriate hypotheses would need to be tested experimentally, which has not yet been done.

The second surprising result was the decrease in amounts of micro-algae where Nerita atramentosa had been excluded around pools. This was completely contradictory to predictions based on previous analyses of grazing and competition by this species (Underwood 1978, 1984b), which demonstrated that amounts of micro-algae were similar in areas grazed by the same number of $N$. atramentosa or of Cellana tramoserica (each species on its own). Even given the increased rate of grazing by $C$. tramoserica in the absence of $N$. atramentosa shown here, no previous work would suggest that $C$. tramoserica would decrease the amounts of chlorophyll compared with areas grazed by N. atramentosa. The decreased amount of chlorophyll where $N$. atramentosa removed could be explained by a facilitatory response of micro-flora to the presence or activities of $N$. atramentosa. Thus, in the presence of snails, standing amounts of micro-algae are enhanced by increased recruitment, growth, productivity or other aspect of their abundance. $N$. atramentosa consume the extra productivity, reducing the standing stock below ungrazed amounts. Where $N$. atramentosa are absent, micro-algal abundance can be greater because of release from grazing, but is reduced compared with grazed areas because the facilitatory influences of the snails were removed. Such facilitation was also proposed as an explanation for patterns of micro-algal abundance when grazed by $N$. atramentosa and Bembicium nanum in laboratory experiments (Murphy \& Underwood 2006).
There are well-documented cases of increased productivity of algae, including micro-algae due to the activity of the grazers. For example, the limpet Patella longicosta maintains a 'garden' of encrusting brown algae (Ralfsia verrucosa) by grazing in irregular swaths through the algae (Branch 1981, McQuaid \& Froneman 1993). This causes more rapid growth at the damaged edges and greater biomass than in ungrazed areas of algae. Whether there are such responses to mechanical damage of micro-flora is unknown.

A second way that grazers could enhance algal productivity is to influence the recruitment and establishment of micro-flora by scraping over the surface. This would positively influence the recruitment from the water-column if the underlying surface were encrusting algae. Some crusts produce antifouling compounds which inhibit the settlement of invertebrates (Nylund \& Pavia 2003) or algae (Wikstrom \& Pavia 2004, Dworjanyn et al. 2006). Grazing could remove the surface of the crusts, reducing the effectiveness of anti-fouling and thereby enhancing growth of micro-algae. Whatever the validity of this concept to the intertidal habitat studied here, it cannot explain the present experimental results because all crusts were removed as part of the experimental procedures.

A third way for gastropod grazers to increase the productivity of micro-algae is by production of mucous trails as they crawl around. The trails persist for some time, showing chemical activity that influences the behaviour of snails (Chapman 1998). Trails can also enhance production or increase survivorship of microalgae (Connor 1986, Davies et al. 1992, Holmes 2005) and can trap propagules of macro-algae (Santelices \& Bobadilla 1996). These influences on micro-algae have not been investigated for Cellana tramoserica or Nerita atramentosa, so it is not known if mucus is involved in enhancing local biomass of micro-flora.

These experiments have revealed some quite unexpected complications in the well-established interactions between gastropods that graze on the same resources. Grazing of microflora by Nerita atramentosa clearly involves some positive, facilitatory processes. Cellana tramoserica may be capable of grazing more than had previously been predicted and are prevented from grazing where $N$. atramentosa are relatively abundant (i.e. near to pools). In this case, the negative interaction between $N$. atramentosa and $C$. tramoserica is positively facilitatory for the micro-algae because they are then present in greater quantities than would be the case if $C$. tramoserica's activities were not reduced. Alternatively, N. tramoserica, in addition to consuming micro-algal resources, have positive, facilitatory effects on production of microflora. When these snails are removed, production and amount of microalgae are reduced. Until these processes are com- 
pletely understood and processes of production are investigated experimentally, the interactions of competition and gardening by the grazers will not be fully interpreted, nor completely predictable.

It has only been possible to begin to understand these processes because of the effectiveness of remotesensing technology able to estimate abundance of the micro-flora at the very small spatial scales at which the interactions have their effects. There are potentially other areas of ecology in which foraging and influences of food-supply may be more completely described by reducing the scale at which observations are made. Cases include those most directly analogous to grazing on rocky shores. For example, grazing by insect larvae on stones in streams or lakes involved interactions among grazers and between grazers and algae at small spatial scales (Harrison \& Hildrew 2001).

There are probably other habitats or species where small-scale differences may influence the choices or rates of encounter with particular resources. Measurements at a larger scale miss these processes because use of or responses to resources will be 'averaged' over the piece of habitat being measured.

Development of techniques for testing hypotheses at smaller-than-previous scales on shores revealed much about previously unknown components. Such developments may be of value in studies of other organisms in other habitats.

Acknowledgements. This study was funded by the Australian Research Council through its Special Centres grants. We are grateful to C. Myers, J. Smith and A. Boden for assistance in the field and to B. Panayotakos for engineering the experimental cages. We thank P. Petraitis and 3 anonymous referees for very helpful comments on the manuscript.

\section{LITERATURE CITED}

Anderson RL (1959) Use of contingency tables in the analysis of consumer preference studies. Biometrics 15:582-590

Bartholomew B (1970) Bare zone between California shrub and grassland communities: the role of animals. Science 170: 1210-1212

Branch GM (1981) The biology of limpets: physical factors, energy flow, and ecological interactions. Oceanogr Mar Biol Annu Rev 19:235-380

Branch GM (1984) Competition between marine organisms: ecological and evolutionary implications. Oceanogr Mar Biol Annu Rev 22:429-593

Brosnan DM (1992) Ecology of tropical rocky shores: plantanimal interactions in tropical and temperate latitudes. In: John DM, Hawkins SJ, Price JH (eds) Plant-animal interactions in the marine benthos. Clarendon Press, Oxford, p 101-131

Brown JH, Whitlam TG, Ernest SKM, Gehring CA (2001) Complex species interactions and the dynamics of ecological systems: long-term experiments. Science 293: 643-650
Chapman MG (1998) Variability in trail-following and aggregation in Nodilittorina unifasciata. J Exp Mar Biol Ecol 224:265-290

Connor V (1986) The use of mucous trails of intertidal limpets to enhance food resources. Biol Bull (Woods Hole) 171: $548-564$

Davies MS, Hawkins SJ, Jones HD (1992) Pedal mucus and its influence on the microbial food supply of two intertidal gastropods, Patella vulgata L. and Littorina littorea (L.). J Exp Mar Biol Ecol 161:57-78

Dayton PK (1971) Competition, disturbance and community organization: the provision and subsequent utilization of space in a rocky intertidal community. Ecol Monogr 41: 351-389

del-Val E, Crawley MJ (2005) What limits herb biomass in grasslands: competition or herbivory? Oecologia 142: 202-211

Dworjanyn SA, deNys R, Steinberg PD (2006) Chemically mediated antifouling in the red alga Delisea pulchra. Mar Ecol Prog Ser 318:153-163

Forrest RE, Chapman MG, Underwood AJ (2001) Quantification of radular marks as a method for estimating grazing of intertidal gastropods on rocky shores. J Exp Mar Biol Ecol 258:155-171

Harrison SSC, Hildrew AG (2001) Epilithic communities and habitat heterogeneity in a lake littoral. J Anim Ecol 70: $692-707$

Hill AS, Hawkins SJ (1991) Seasonal and spatial variation of epilithic microalgal distribution and abundance and its ingestion by Patella vulgata on a moderately exposed rocky shore. J Mar Biol Assoc UK 71:403-423

Holmes SP (2005) The effect of Patella vulgata pedal mucus on the settlement and development or propagation of Skeletonema costatum and Fucus spiralis. J Molluscan Stud 71:53-57

Huntley N (1991) Herbivores and the dynamics of communities and ecosystems. Annu Rev Ecol Syst 22:477-503

Kaehler S, Froneman PW (2002) Herbivore-mediated increase in the photosynthetic capacity of marine biofilms: indirect effects of changing microalgal species composition. Mar Ecol Prog Ser 234:15-22

Levings SC, Garrity SD (1983) Diel and tidal movement of two co-occurring Neritid snails; differences in grazing patterns on a tropical rocky shore. J Exp Mar Biol Ecol 67:261-278

Macia S, Robinson MP (2005) Effects of habitat heterogeneity in seagrass beds on grazing patterns of parrotfishes. Mar Ecol Prog Ser 303:113-121

Mackay DA, Underwood AJ (1977) Experimental studies on homing in the intertidal patellid limpet Cellana tramoserica (Sowerby). Oecologia 30:215-238

MacLulich JH (1986) Colonization of bare rock surfaces by microflora in a rocky intertidal habitat. Mar Ecol Prog Ser 32:91-96

McIntire EJB, Hik DS (2005) Influences of chronic and current season grazing by collared pikas on above ground biomass and species richness in subarctic alpine meadows. Oecologia 145:288-297

McQuaid CD, Froneman PW (1993) Mutualism between the territorial intertidal limpet Patella longicosta and the crustose alga Ralfsia verrucosa. Oecologia 96:128-133

Murphy RJ, Underwood AJ (2006) Novel use of colour-infrared imagery to test hypotheses about grazing by intertidal herbivorous gastropods. J Exp Mar Biol Ecol 330:437-447

Murphy RJ, Tolhurst TJ, Chapman MG, Underwood AJ (2004) Estimation of surface chlorophyll on an exposed mudflat using digital colour infrared (CIR) photography. Estuar Coast Shelf Sci 59:625-638 
Murphy RJ, Underwood AJ, Pinkerton MH (2006) Quantitative imaging to measure photosynthetic biomass on an intertidal rock-platform. Mar Ecol Prog Ser 312:45-55

Nylund GM, Pavia H (2003) Inhibitory effects of red algal extracts on larval settlement of the barnacle Balanus improvisus. Mar Biol 143:875-882

Ogden JC, Brown RA, Salesky N (1973) Grazing by the echinoid Diadema antillarum Philippi: formation of halos around West Indian Patch Reefs. Science 182:715-717

Pace ML, Cole JJ, Carpenter SR, Kitchell JF (1999) Trophic cascades revealed in diverse ecosystems. Trends Ecol Evol $14: 483-488$

Santelices B, Bobadilla M (1996) Gastropod pedal mucus retains seaweed propagules. J Exp Mar Biol Ecol 197: 251-261

Stafford R, Davis MS (2005) Spatial patchiness of epilithic biofilm caused by refuge-inhabiting high shore gastropods. Hydrobiologia 545:279-287

Stimson J (1973) The role of the territory in the ecology of the intertidal limpet Lottia gigantea (Gray). Ecology 54: $1020-1030$

Thompson RC, Johnson LE, Hawkins SJ (1997) A method for spatial and temporal assessment of gastropod grazing intensity in the field: the use of radula scrapes on wax surfaces. J Exp Mar Biol Ecol 218:63-76

Underwood AJ (1978) An experimental evaluation of competition between three species of intertidal prosobranch gastropods. Oecologia 33:185-208

Underwood AJ (1980) The effects of grazing by gastropods and physical factors on the upper limits of distribution of intertidal macroalgae. Oecologia 46:201-213

Underwood AJ (1984a) Vertical and seasonal patterns in competition for microalgae between intertidal gastropods. Oecologia 64:211-222

Underwood AJ (1984b) The vertical distribution and seasonal abundance of intertidal microalgae on a rocky shore in New South Wales. J Exp Mar Biol Ecol 78:199-220

Editorial responsibility: Roger Hughes, Bangor, UK
Underwood AJ (1988) Design and analysis of field experiments on competitive interactions affecting behaviour of intertidal animals. In: Vannini GCM (ed) Behavioural adaptation to intertidal life. Plenum Press, New York, p 333-358

Underwood AJ (1997) Experiments in ecology: their logical design and interpretation using analysis of variance. Cambridge University Press, Cambridge

Underwood AJ, Creese RG (1976) Observations on the biology of the trochid gastropod Austrocochlea constricta (Lamarck) (Prosobranchia). II. The effects of available food on shell-banding pattern. J Exp Mar Biol Ecol 23: $229-240$

Underwood AJ, Denley EJ (1984) Paradigms, explanations and generalisations in models for the structure of intertidal communities on rocky shores. In: Strong DR, Simberloff D, Abele LG, Thistle AB (eds) Ecological communities: conceptual issues and the evidence. Princeton University Press, Princeton, NJ, p 151-180

Underwood AJ, Skilleter GA (1996) Effects of patch-size on the structure of assemblages on rock pools. J Exp Mar Biol Ecol 197:63-90

Whicker AD, Detling JK (1988) Ecological consequences of prairie dog disturbances. Bioscience 38:778-785

Wikstrom SA, Pavia H (2004) Chemical settlement inhibition versus post-settlement mortality as an explanation for differential fouling of two congeneric seaweeds. Oecologia 138:223-230

Williams GA, Davies MS, Nagarkar S (2000) Primary succession on a seasonal tropical rocky shore: the relative roles of spatial heterogeneity and herbivory. Mar Ecol Prog Ser 203:81-94

Wright WG (1982) Ritualized behaviour in a territorial limpet. J Exp Mar Biol Ecol 60:245-252

Wright WG, Shanks AL (1993) Previous experience determines territorial behavior in an archaeogastropod limpet. J Exp Mar Biol Ecol 166:217-229

Submitted: July 5, 2007; Accepted: October 24, 2007

Proofs received from author(s): March 27, 2008 